Article

\title{
The Economic Viability of Renewable Portfolio Standard Support for Offshore Wind Farm Projects in Korea
}

\section{Chang-Gi Min ${ }^{1}$, Jong Keun Park ${ }^{1, *}$, Don Hur ${ }^{2}$ and Mun-Kyeom Kim ${ }^{3}$}

1 Department of Electrical and Computer Engineering, Seoul National University, 599 Gwanak-ro, Gwanak-gu, Seoul 151-744, Korea; E-Mail: cgmin@snu.ac.kr

2 Department of Electrical Engineering, Kwangwoon University, 20 Kwangwoon-ro 20, Nowon-gu, Seoul 139-701, Korea; E-Mail: dhur@kw.ac.kr

3 Department of Energy System Engineering, Chung-Ang University, 84 Heukseok-ro, Dongjak-gu, Seoul 156-756, Korea; E-Mail: mkim@cau.ac.kr

* Author to whom correspondence should be addressed; E-Mail: parkjk@snu.ac.kr; Tel.: +82-2-880-7258; Fax: +82-2-878-1452.

Academic Editor: Simon J. Watson

Received: 20 May 2015 / Accepted: 1 September 2015 / Published: 9 September 2015

\begin{abstract}
Offshore wind farm (WF) projects have been promoted by support schemes as part of the expansion of renewable energy resources in Korea. This paper examines in detail how the Renewable Portfolio Standard (RPS), which was adopted post the Feed-in-Tariff scheme in 2012, has had a profound impact on the economic benefits of offshore WFs in Korea. A framework for analyzing the economic viability of RPS is presented and applied to the sixth basic plan for long-term electricity supply and demand in Korea. The electricity market price is forecast using a reformulated probabilistic production cost (PPC) model, and the renewable energy certificate (REC) price is calculated using its determination rule. The results show that the existing RPS will be ineffective in increasing the penetration of offshore WFs in Korea; however, they also indicate that the economic viability of offshore WFs could be improved by adjusting the existing RPS.
\end{abstract}

Keywords: economic viability; offshore wind farm; renewable energy resources; renewable portfolio standard; support schemes 


\section{Introduction}

The Korean government has recently announced an expansion plan for renewable energy resources that entails an increase of at least $20 \%$ in national installed generation capacity by 2027 . Wind power is expected to be a particularly important part of this plan, and the fraction of wind power is planned to amount to $53 \%$ of the total renewable generation capacity in 2027, with an additional $1250 \mathrm{MW}$ each year [1]. Of the wind farm (WF) projects that are already established (representing a generation capacity of $11,970 \mathrm{MW}), 72 \%$ are situated in offshore areas, which are advantageous compared with onshore areas in terms of political acceptability because of the reduced opposition from local residents. An example is the $2500 \mathrm{MW}$ offshore WF currently under construction in the southwest of the Korean peninsula [2]. An $80 \mathrm{MW}$ test site was originally scheduled for completion in 2014, with a $420 \mathrm{MW}$ demonstration site online by 2016 and the remaining generation capacity by 2019 . The required investment totaled 9.2 trillion won of private and public joint funding. The area that will be occupied by the site is approximately $226 \mathrm{~km}^{2}$ and it is located $200 \mathrm{~km}$ from the center of Seoul. This demonstrates the Korean government's intention to increase the penetration of renewable energy through the strategic promotion of the large-scale offshore WFs.

Private investors in Korea may be reluctant to invest in offshore WF projects without the benefit of economic support schemes. The feed-in tariff (FIT), which was established in 2002 and maintained until 2011 [3] has contributed to providing a financial footing for the penetration of the wind energy [4]. Following this initiative, the renewable portfolio standard (RPS), which came into effect in April 2012, addressed problems inherent in FIT, including the government's financial crunch and difficulties in estimating adequate pricing. The renewable energy certificate (REC) trading market connected to the RPS was also introduced in 2012. It is currently in a transitional phase, with limited enforcement; however, it will become active through phased expansion [5]. It should be noted that the RPS appears to have been designed to make offshore WFs more lucrative than the other renewable energy resources, as the largest REC weighting is given to the offshore WFs. As the REC market stabilizes, there is little doubt that it will become an important stream of income for offshore WFs.

A quantitative analysis of the impact of RPS on the profitability of offshore WF projects is a matter of some urgency, as the REC price reached $180 \%$ of electricity market price in 2013 [6]. Moreover, the electricity market price will vary with the penetration of renewable energy resources, including wind and photovoltaic (PV) power [7-12]. Unfortunately, relatively little research has been devoted to the economic viability of RPS in tandem with these revenue elements [13-16]. It is of importance to be able to seamlessly capture the REC price as well as the electricity market price.

In this paper, we present a framework for the analysis of the economic viability of RPS considering long-term variation in revenue elements. We also examine the possible options for improving existing RPS from the viewpoint of private investors in offshore WF projects in Korea. The electricity market price is forecast using a reformulated probabilistic production cost (PPC) model [17] and the REC price is calculated using its determination rule [18]. The results of these simulations provide not only insight into the economic viability of the RPS in Korea but also a basis for adjusting the RPS considering potential changes in the circumstances related to renewable energy penetration.

The remainder of the paper is organized as follows: in Section 2, we present a method for long-term prediction of electricity market prices. Section 3 covers the prediction of REC price. In Section 4 , 
we describe a method for assessing the annual production of wind energy. Section 5 gives a summary of the revenue and cost elements of offshore WF projects. Section 6 provides details of the metrics used in the economic evaluation. In Section 7, we discuss numerical results for two different scenarios, and concluding remarks are given in Section 8.

\section{Predicting the Market Price of Electricity}

The electricity market price is determined based on so-called "merit order", which is a method of ranking generators in ascending order of short-run marginal costs to meet the required load every hour, so that the unit with the lowest marginal cost has priority to be brought on line. It follows that if most of the available renewable power plants with no fuel costs, such as wind and PV power plants, are ranked highest, then other generators are settled in sequence of their own marginal costs. Allowing for this prioritization mechanism, it is expected that an increase in renewable power plants participating in the electricity markets will tend to lower market prices by pushing up the merit order stacks of conventional generators. The growing number of renewable power plants and the consequent impact on the electricity market price are important considerations in predicting the market price.

The influence of those resources on the market price prediction process is contingent upon the type of the renewable energy resources, which are classified as variable generation sources and non-variable generation sources. Biofuel, waste, and blast furnace gas (BFG) generation belong to the latter category, and these can be treated in the same manner as conventional generators. Variable generation sources such as wind and PV power should be addressed in a different manner from conventional generators. These sources are currently scheduled to account for $70 \%$ of the renewable energy resources in Korea by 2027 [1].

A few studies have examined methods of predicting market prices considering variable generation sources based on the market clearing process in the long-term [17,19,20]. Most used probabilistic approaches to consider the effects of long-term expansion of variable generation sources on electricity market prices. The most common approach is PPC model, which is favorable to chronological methods in terms of applicability [21,22]. In this paper, we use the PPC-based prediction model [17], which was reformulated to take into account the effects of variable generation sources.

With the PPC-based prediction model, variable generation sources are regarded as units of generation, which are committed according to their merit order. Allowing for the uncertainties inherent in loads and conventional generators, as well as the variable generation sources, each generator aligned in merit order may be a marginal generator; thus, the number of possible market prices is the same as the total number of generators. All generators may therefore necessarily be marginal generators because of the possibility of sudden failure of generators and unpredicted changes in the load and output power of variable generation sources. The expected market price can then be forecast by taking advantage of available information on the probability distribution of market prices. Predicting the market price relies on the concept of an equivalent load, which is obtained by convolving probability density functions (PDFs). The PDF of equivalent loads with $M$ WFs and $N$ PV farms (PFs) can be obtained by convolving the PDFs of the annual hourly load and the output of each WF and PF, i.e.:

$$
f_{W P}=f_{L} * f_{W, 1} * f_{W, 2} * \cdots * f_{W, M-1} * f_{W, M} * f_{P, 1} * f_{P, 2} * \cdots * f_{P, N-1} * f_{P, N}
$$


where the PDFs of the original load and the equivalent load incorporating $M$ WFs and $N$ PFs are expressed by $f_{L}$ and $f_{W P}$, respectively, so that $f_{W}, \#$ denotes the PDF of the output of each WF multiplied by -1 , and $f_{P, \#}$ is the PDF of the output of each PF multiplied by -1 . The PDF of the equivalent load for each conventional generator can be calculated according to the merit order, i.e.:

$$
f_{i}=f_{W P} * f_{C, 1} * f_{C, 2} * \cdots * f_{C, i-2} * f_{C, i-1}
$$

where the PDF of the equivalent load of $i$ th conventional generator is represented by $f_{i}$, and the PDF of the unavailable capacity of $i$ th conventional generator is $f_{C, i}$. In Equation (2), the PDF of the equivalent load for $i$ th conventional generator in the merit order is calculated by convolving the PDFs of all the previous conventional generators with the PDF of the equivalent load incorporating all of the WFs and PFs.

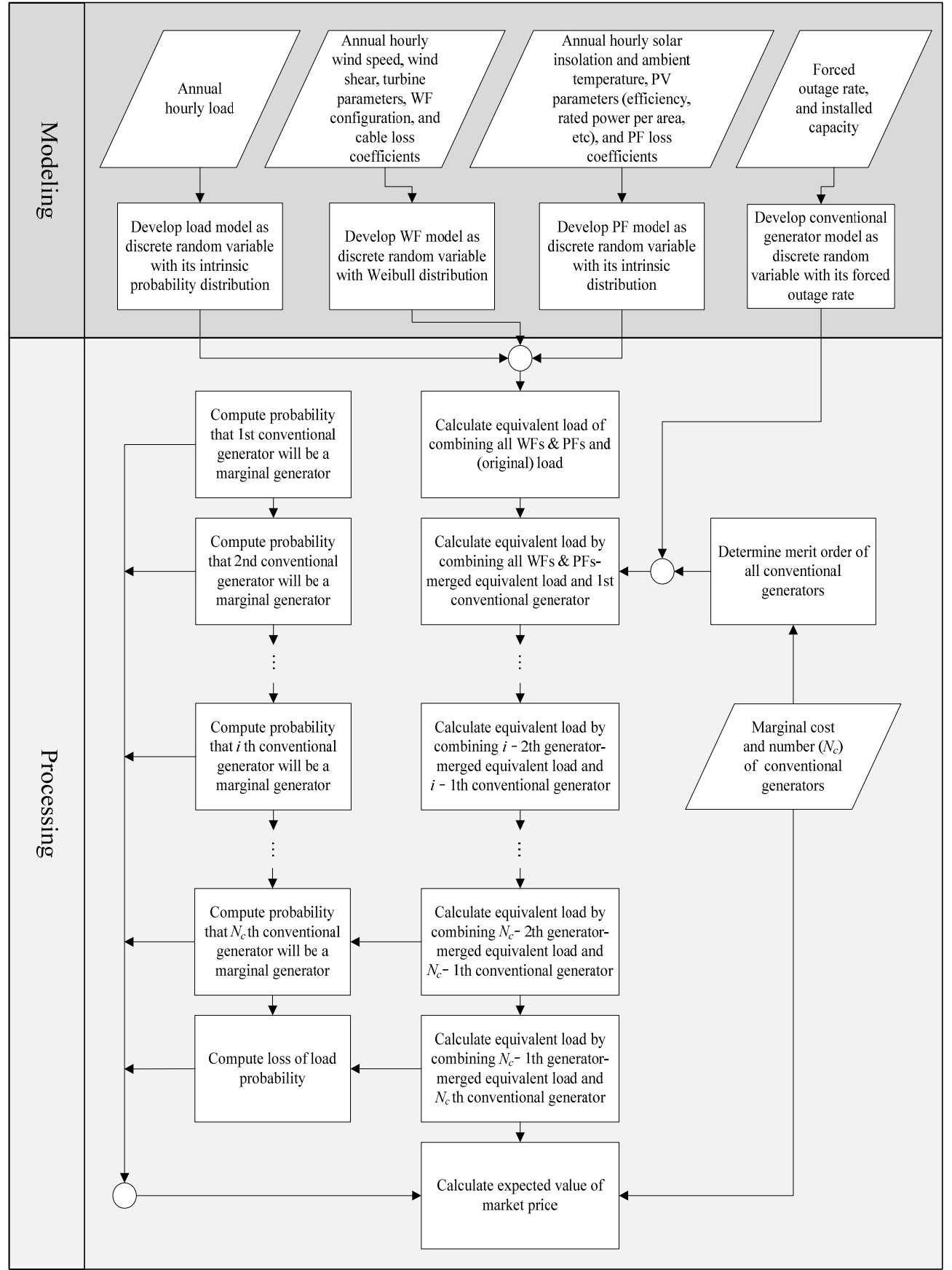

Figure 1. The procedure used to predict the market price. 
The probability that a given generator will be selected as a marginal unit in the market clearing process is determined from the probability that the generator considered meets the equivalent load and is available. The probability that the $i$ th conventional generator will be a marginal generator is therefore given by:

$$
p r_{i}=\int_{C_{i-1}}^{C_{i}} f_{i-1} d L \times\left(1-F O R_{i}\right)
$$

where $C_{i}$ is the cumulative sum of the installed capacities of all generators up to the $i$ th conventional generator, $d L$ is an infinitesimal increment in the load, and $F O R_{i}$ is the forced outage rate of the $i$ th conventional generator. The expected marginal cost of all marginal generators is then equal to the market price. This procedure is illustrated by the flow chart shown in Figure 1.

\section{Predicting the REC (Renewable Energy Certificate) Price}

The RPS imposes a levy on electric power producers (EPPs) for energy that is certified to be $100 \%$ generated using renewable energy resources. Currently, in Korea, there are thirteen EPPs that are obliged to supply at least $10 \%$ of their annual energy production from renewable energy resources until 2022 by maintaining an annual increase, as listed in Table 1 [23]. The EPP can purchase energy to make up for a shortfall in the required quantity via the REC spot market to avoid penalties of up to $150 \%$ of the REC spot price.

Table 1. Mandatory minimum fraction (MMF) of renewable energy for EPPs under the RPS in Korea.

\begin{tabular}{ccccccccc}
\hline Year & $\mathbf{2 0 1 5}$ & $\mathbf{2 0 1 6}$ & $\mathbf{2 0 1 7}$ & $\mathbf{2 0 1 8}$ & $\mathbf{2 0 1 9}$ & $\mathbf{2 0 2 0}$ & $\mathbf{2 0 2 1}$ & After 2021 \\
\hline Fraction of renewable energy & $3.5 \%$ & $4 \%$ & $5 \%$ & $6 \%$ & $7 \%$ & $8 \%$ & $9 \%$ & $10 \%$ \\
\hline
\end{tabular}

The REC spot price functions as a standard pricing benchmark for REC transactions, as well as a penalty; thus, the REC spot market is considered representative. The spot price is settled by the market clearing process, which is similar to the CBP-based electricity market [5]. Demand in the REC spot market is based on the given mandatory minimum fraction (MMF) and energy production by EPPs. The REC demand in megawatt-hours for each year may be calculated as follows:

$$
\text { REC demand }=E P P s^{\prime} \text { total energy production } \times M M F
$$

If the renewable energy resources are classified according to the energy type via a clustering technique, then the REC supply for each energy type for each year may be expressed as follows:

$$
\text { REC supply }_{k}=\text { Energy production }_{k} \times \text { REC weighting }_{k}
$$

in units of megawatt-hours, where $k$ represents the index for the type of renewable energy resource. The REC weighting varies from 0.25 to 2.0 depending on the energy type, and the largest weighting (i.e., 2.0) is assigned to offshore WFs that are more than $5 \mathrm{~km}$ offshore. The marginal cost for each energy type in each year can be calculated as follows:

$$
\text { Marginal cost }_{k}=\frac{L_{C O E_{k}}}{R E C \text { weighting }}{ }_{k}-\text { Electricitymarket price }
$$


which is in units of dollars per megawatt-hour, where the levelized cost of energy (LCOE; this will be discussed further in Section 6) is used to calculate the marginal cost for each energy type, which corresponds to a bidding price on the REC spot market. The REC market is divided into two separate markets in Korea, i.e., PV energy and non-PV energy. Here, we restrict ourselves to the non-PV energy market in which the offshore WFs can participate.

\section{Assessment of Wind Energy Production}

The revenue from wind power can be represented by the product of the annual wind energy production (AWEP) and the market price for electricity. Here, we describe the concept of the AWEP calculated via the multi-phased procedure [24]. First, the hourly wind speed at the hub height of the wind turbines (WTs) is calculated from the measured wind speed at an arbitrary height and the wind shear. The Weibull distribution of hourly wind speeds at hub height was calculated using the wblfit() function of Matlab R2012a. The mechanical power was determined using the wind speed at the hub and the available electrical power was then obtained by subtracting the conversion losses occurring inside the generator. Details of loss coefficients and the relationship between the mechanical power and the conversion losses are given in [24]. The AWEP of the WF was then calculated considering the configuration of the WF. We consider submarine cable losses in transmission from the WF to the onshore substation. In each WF, if the correlation coefficient among the output of the WTs in the WF is statistically significant (i.e., greater than 0.8), then the output power of individual WTs was assumed to be uniform throughout the WF. The AWEP of a WF is as follows:

$$
\begin{aligned}
A W E P_{W F} & =\text { Number of WTs } \times(1-\text { Internal cable loss coefficient }) \\
& \times(1-\text { External cable loss coefficient }) \times A W E P_{W T}
\end{aligned}
$$

where $A W E P_{W F}$ is the AWEP of an individual WF in units of megawatt-hours.

\section{Revenue and Cost for Offshore Wind Farms}

Revenue for offshore WFs in Korea currently comes from the REC trading market and the electricity wholesale market. It may be defined as follows:

$$
\text { Revenue }=\sum_{t=0} \frac{\left(\text { Electricitymarket price }_{t}+\text { REC price }_{t} \times R E C \text { weighting }\right) \times A W E P_{W F, t}}{\left(1+\text { Discount rate }^{t}\right.}
$$

where the subscript $t$ denotes the year of operation, and the zero year corresponds to the start of the scheme. The denominators in the right-hand side are used to obtain present values.

The cost model for offshore WFs in [25] was used to describe the capital expenditure as a function of the primary offshore conditions, including the distance to shore and depth of the water. For example, cost factors for the external submarine cables and foundations vary with the distance to shore and the depth of the water.

\section{Metrics of Economic Evaluation}

The net present value (NPV) and the internal rate of return (IRR) are typically used as profitability indices for capital-budget decisions. The NPV is defined as the present value of the sum of net cash 
flows, i.e., income minus costs over a given time period. Here, the costs incorporate servicing debt, income taxes, and operating costs. Income taxes correspond to the product of the tax rate and some value that is obtained by subtracting debt interest payments, depreciation, and operations costs from the annual income. An investment plan with a negative NPV cannot be financially justified. An alternative with a larger NPV is preferred, unless there are constraints on the capital investment. The IRR is the break-even discount rate that makes the NPV zero. If all other factors are equal among more than two projects, the project with the largest IRR will have the highest priority and will be launched first.

The LCOE is defined as the total costs of energy-related project, normalized to the electricity production over its lifetime, expressed as follows:

$$
\begin{aligned}
& \operatorname{LCOE}(\$ / M W h)=\frac{\text { Investment } \cos t_{0}+\sum_{t=1}^{T} \frac{{\text { Annual } \cos t_{t}}_{\left(1+\text { Discout rate }^{t}\right.}}{(1-\text { Tax rate })}}{\sum_{t=1}^{T} \frac{\text { Annual energy production }_{t}}{(1+\text { Discout rate })^{t}}} \\
& -\frac{\sum_{t=1}^{T} \frac{\text { Depreciated value }_{t}}{\left(1+{\text { Discout rate })^{t}}_{\text {Tax }}\right. \text { rate }}}{\sum_{t=1}^{T} \frac{\text { Annual energy production }_{t}}{(1+\text { Discout rate })^{t}}}
\end{aligned}
$$

Tax deductions for debt interest payments and depreciation are taken into account, as shown in the numerator of Equation (9). Furthermore, the residual values associated with the project are assumed to be zero at the end of its lifetime.

\section{Case Study}

In Korea, Jeju Island comprises a small self-contained electric power network that is distinguished from non-Jeju regions by the electricity market price and REC price. In this paper, we are only concerned with non-Jeju regions to which the offshore WF of interest belongs. Based on the sixth basic plan for long-term electricity supply and demand [1], scenarios for the installed capacity and annual peak demand until 2035 were created as shown in Figure 2, using extrapolation tools in Microsoft Excel 2013. The cumulative installed capacity up to 2015 is shown in Table 2, and the annual variation in the installed capacity by fuel type from 2016 to 2035 is given in Table 3 .

Planned construction of new facilities and decommissioning of existing facilities determine the number units of each fuel type shown in Figure 3, where the data were taken from [1]. The forced outage rate (FOR) and marginal cost of new generators coming on line in 2016 during the first year of operation are listed in Table 4 by fuel type [26]. We assume that the marginal cost of all generators varies with the fuel price each year, and the FORs are fixed during the whole period. Each fuel price is shown in Figure 4 [27]. The value of lost load (VoLL) for each year was arbitrarily set to 10 times the maximum marginal cost to a minimum [28]. We use information on the installed capacity and the FOR of individual generators to organize the PDFs of the unavailable capacity. 


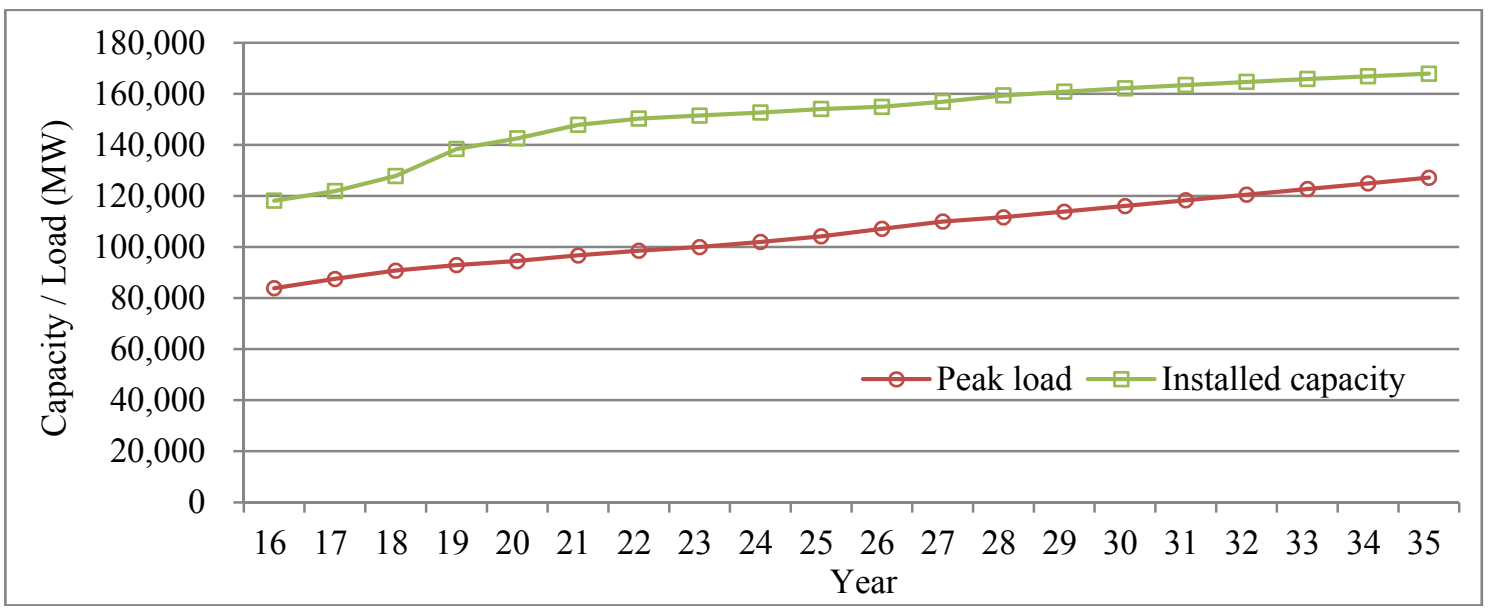

Figure 2. Installed capacity and annual peak demand.

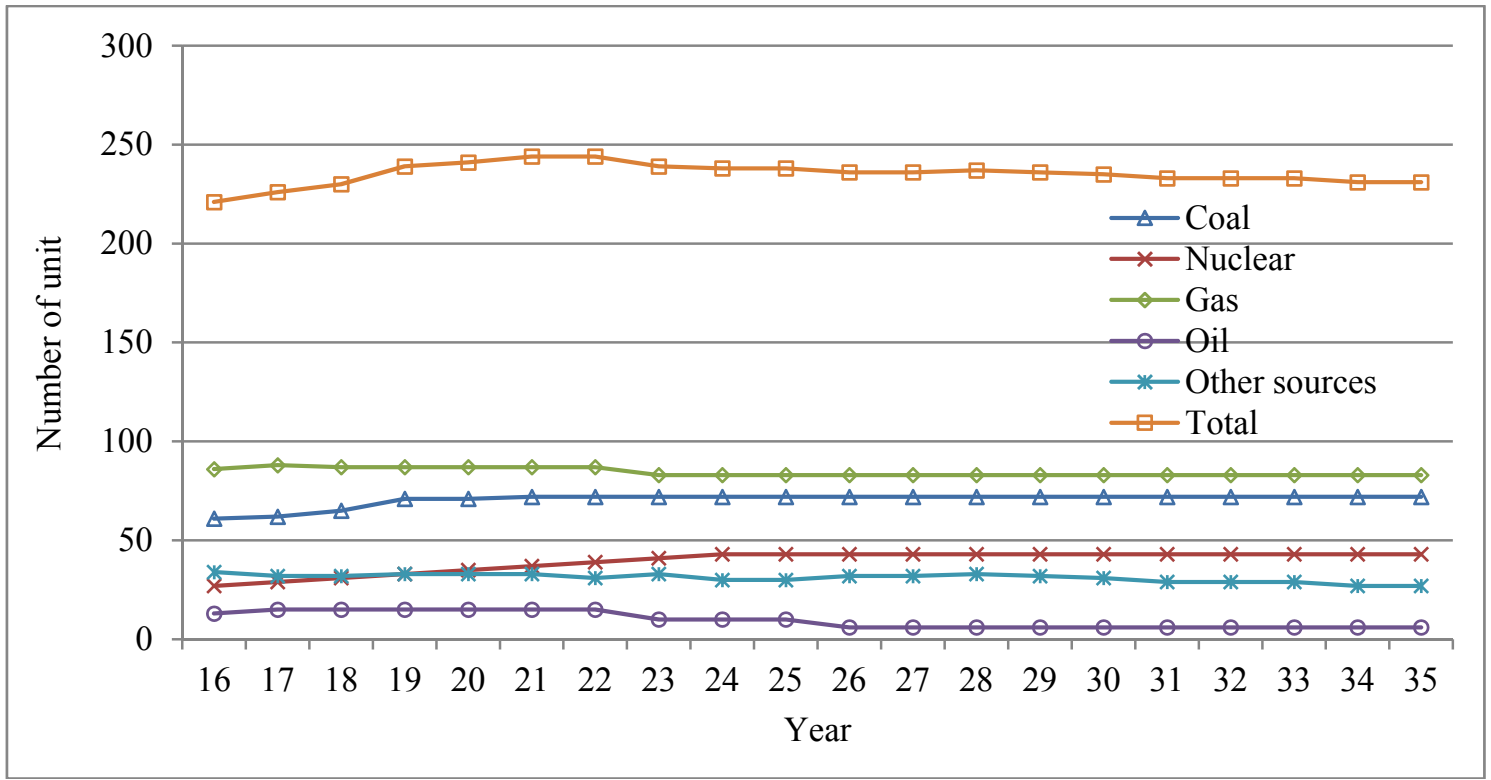

Figure 3. Planned installed capacity from 2016 to 2035 .

Table 2. Installed capacity in 2015.

\begin{tabular}{ccc}
\hline Fuel Type & Capacity (MW) \\
\hline Nuclear & 24,516 \\
Coal & 28,294 \\
Gas & 31,372 \\
Oil & 3161 \\
\hline & Wind & 3286 \\
Renewable energy & Solar & 1807 \\
& Other & 3610 \\
\hline \multicolumn{2}{c}{ Other sources } & 11,073 \\
Total installed capacity & 107,119 \\
\hline
\end{tabular}


Table 3. Planned changes in the installed capacity from 2016 to 2035 . A negative quantity indicates the decommissioning of existing generators.

\begin{tabular}{|c|c|c|c|c|c|c|c|c|c|}
\hline \multirow[b]{2}{*}{ Year } & \multirow{2}{*}{$\begin{array}{c}\text { Nuclear } \\
\text { (MW) }\end{array}$} & \multirow[b]{2}{*}{$\begin{array}{c}\text { Coal } \\
(\mathbf{M W})\end{array}$} & \multirow[b]{2}{*}{$\begin{array}{c}\text { Gas } \\
(\mathrm{MW})\end{array}$} & \multirow[b]{2}{*}{$\begin{array}{c}\text { Oil } \\
(\mathbf{M W})\end{array}$} & \multicolumn{3}{|c|}{ Renewable Energy } & \multirow{2}{*}{$\begin{array}{c}\text { Other } \\
\text { Sources } \\
\text { (MW) } \\
\end{array}$} & \multirow{2}{*}{$\begin{array}{c}\text { Total Installed } \\
\text { Capacity } \\
\text { (MW) }\end{array}$} \\
\hline & & & & & $\begin{array}{l}\text { Wind } \\
(\mathrm{MW})\end{array}$ & $\begin{array}{l}\text { Solar } \\
(\mathrm{MW})\end{array}$ & $\begin{array}{l}\text { Other } \\
\text { (MW) }\end{array}$ & & \\
\hline 2016 & 0 & 7760 & 1752 & -809 & 1070 & 1 & 109 & 1127 & 118,129 \\
\hline 2017 & 1400 & 600 & 950 & 812 & 485 & 4 & 334 & -810 & 121,904 \\
\hline 2018 & 1400 & 2370 & -480 & 0 & 2430 & 0 & 200 & 1 & 127,825 \\
\hline 2019 & 1400 & 5370 & 0 & 0 & 2246 & 32 & 743 & 744 & 138,360 \\
\hline 2020 & 1400 & 0 & 0 & 0 & 1506 & 9 & 1256 & 3 & 142,534 \\
\hline 2021 & 1400 & 1000 & 0 & 0 & 2700 & 0 & 206 & -3 & 147,837 \\
\hline 2022 & 1400 & 0 & 0 & 0 & 1880 & 70 & 289 & -1200 & 150,276 \\
\hline 2023 & 1500 & 0 & -1800 & -1200 & 450 & 795 & 238 & 1200 & 151,459 \\
\hline 2024 & 1500 & 0 & 0 & 0 & 0 & 840 & 240 & -1400 & 152,639 \\
\hline 2025 & 0 & 0 & 0 & 0 & 0 & 863 & 541 & 0 & 154,043 \\
\hline 2026 & 0 & 0 & 0 & -1400 & 0 & 0 & 876 & 1400 & 154,919 \\
\hline 2027 & 0 & 0 & 0 & 0 & 1222 & 993 & -255 & 0 & 156,879 \\
\hline 2028 & 0 & 0 & 0 & 0 & 715 & 565 & 272 & 922 & 159,353 \\
\hline 2029 & 0 & 0 & 0 & 0 & 699 & 521 & 284 & -50 & 160,806 \\
\hline 2030 & 0 & 0 & 0 & 0 & 681 & 476 & 299 & -96 & 162,166 \\
\hline 2031 & 0 & 0 & 0 & 0 & 661 & 432 & 315 & -130 & 163,443 \\
\hline 2032 & 0 & 0 & 0 & 0 & 639 & 387 & 333 & -155 & 164,647 \\
\hline 2033 & 0 & 0 & 0 & 0 & 615 & 343 & 353 & -172 & 165,786 \\
\hline 2034 & 0 & 0 & 0 & 0 & 591 & 299 & 374 & -182 & 166,867 \\
\hline 2035 & 0 & 0 & 0 & 0 & 565 & 254 & 396 & -187 & 167,895 \\
\hline
\end{tabular}

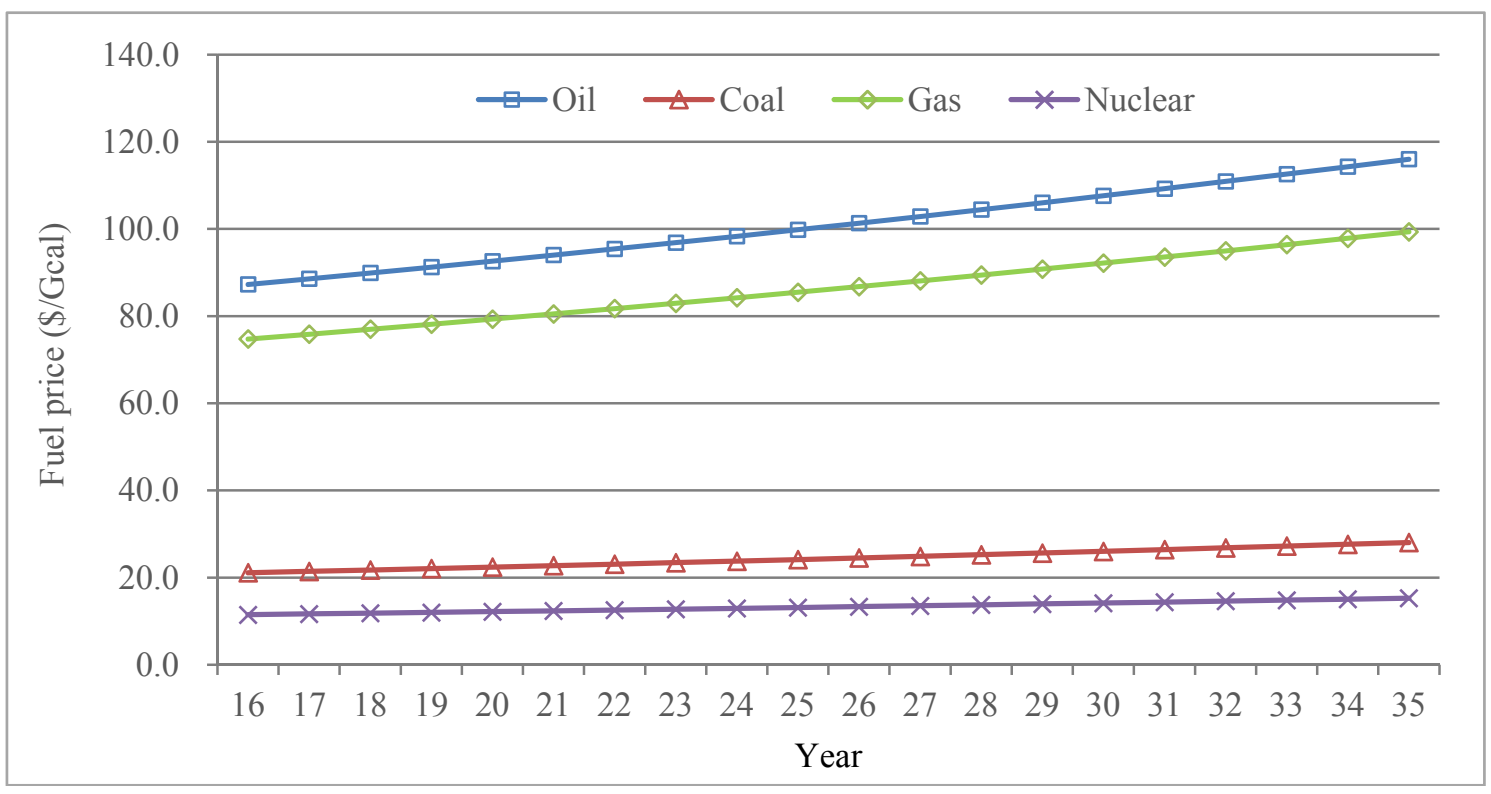

Figure 4. Predicted fuel price. 
Table 4. New conventional generators in 2016.

\begin{tabular}{|c|c|c|}
\hline Fuel Type & Marginal Cost $(\$ / k W h)$ & FOR \\
\hline Coal & 0.0289 & 0.048 \\
\hline Gas & 0.1522 & 0.07 \\
\hline Oil & 0.1160 & 0.05 \\
\hline Other & 0.0058 & 0.015 \\
\hline
\end{tabular}

To calculate the probabilistic distribution of the output of PFs, 10 representative areas were selected based on the 20-year averaged data for insolation at 22 measurement locations, and the installation size for each area was determined in proportion to the PV insolation intensity [29]. Figure 5 shows the PDFs of the output of PFs in the selected area in 2016. Historical data for the temperature and insolation at each area and the applied PV information, including efficiency, rated power, and loss coefficients, were used to calculate the output distribution of PFs for each year [30-32].
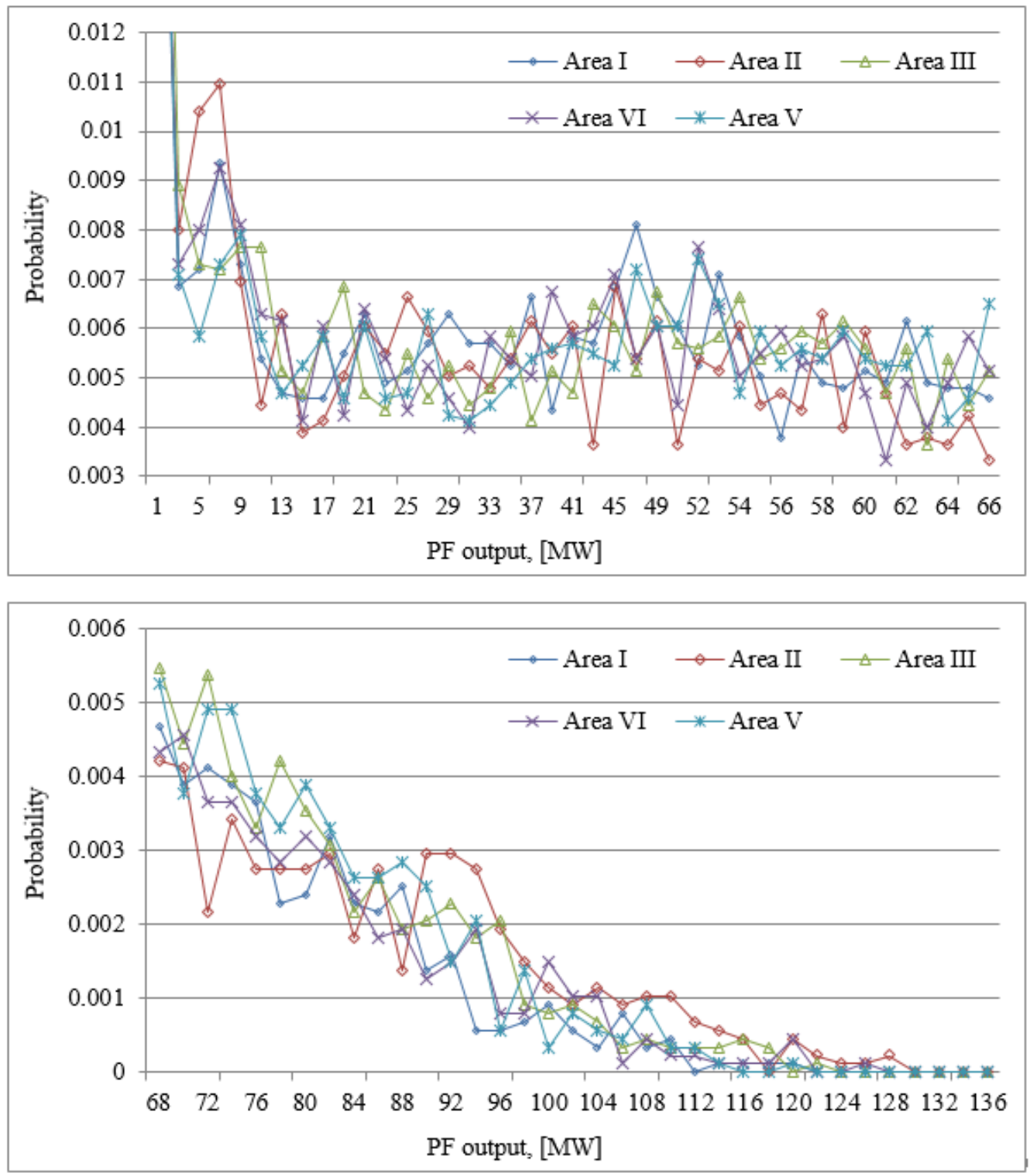

(a)

Figure 5. Cont. 

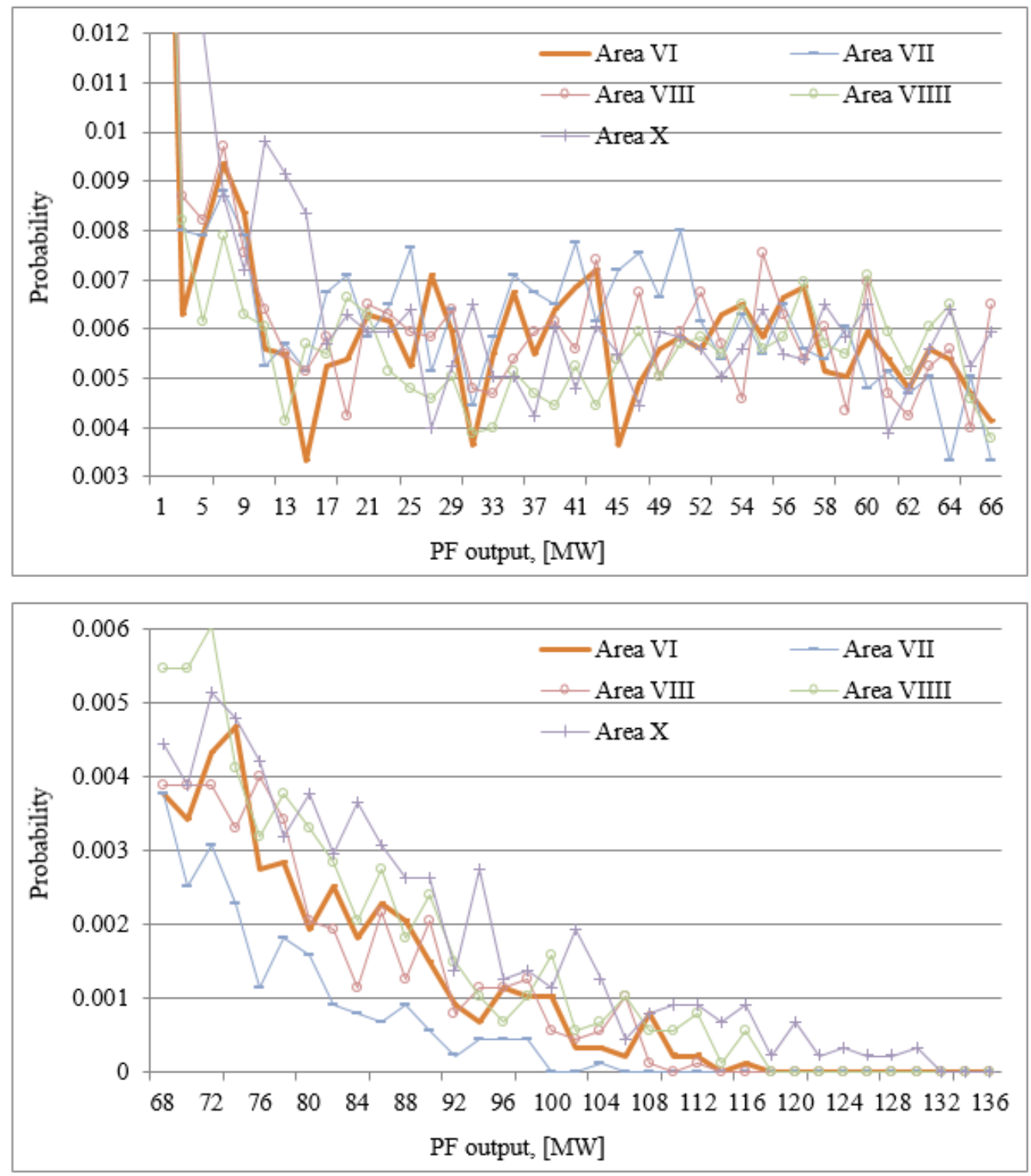

(b)

Figure 5. (a) PDFs of PFs in 5 classified areas (Area I Area V) in 2016; (b) PDFs of PFs in 5 classified areas (Area VI Area X) in 2016.

The candidate regions for WFs may be categorized into three groups based on the data for the wind power density [33] and existing WF construction plans, as shown in Figure 6. It was assumed that 5 MW and 2 MW WTs are installed in these regions [34,35]. The annual average wind speed, the shape parameter of the Weibull distribution, and the capacity factor for each of the regions are shown in Table 5; these data were obtained from wind speed data at 23 measurement locations [36]. The offshore WF was located at Buan-gun in region II, where the water depth is $12 \mathrm{~m}$ and the distance to shore is $15 \mathrm{~km}$ [37]. Table 6 provides a summary of the available data on the WF of interest, including the associated WTs and the foundations [38,39]. Table 7 lists the fiscal assumptions used to achieve an economic comparison [40]. The electricity market prices were calculated using these data, as shown in Figure 7. Compared with the market data, the expected market price was smaller by $20 \%-40 \%$ due to the fact that the reserve ratio increased sharply after 2014 and was then maintained at approximately three times higher than that in 2013 [41]. 


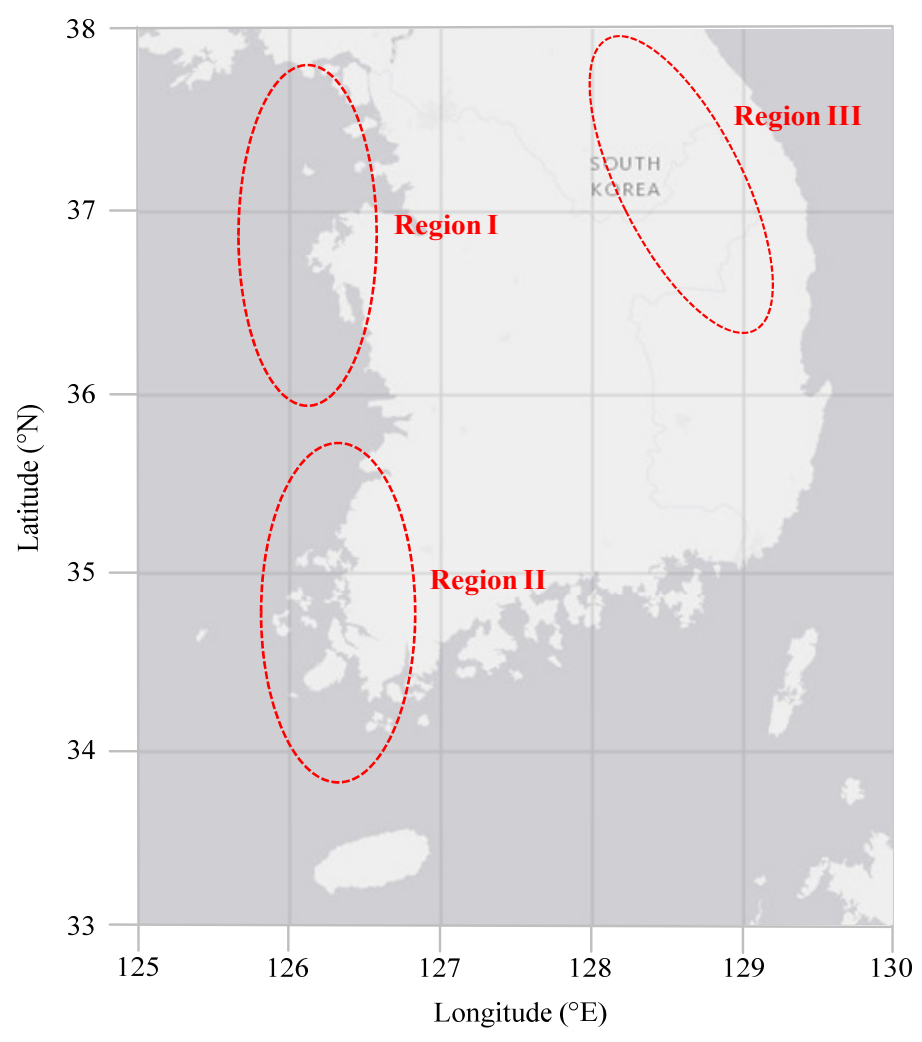

Figure 6. Three candidate regions for WFs.

Table 5. Annual average wind speed and capacity factor for each region.

\begin{tabular}{cccc}
\hline Region & Average Wind Speed $(\mathbf{m} / \mathbf{s})$ & Shape Parameter & Capacity Factor \\
\hline I & 5.925 & 1.8887 & $24.3 \%$ \\
II & 6.300 & 1.8091 & $27.8 \%$ \\
III & 7.073 & 1.3526 & $30.8 \%$ \\
\hline
\end{tabular}

Table 6. Detailed parameters for the wind farm of interest.

\begin{tabular}{|c|c|}
\hline Term & Description \\
\hline \multicolumn{2}{|r|}{ Wind turbine } \\
\hline Model & NREL 5-MW Baseline WT \\
\hline Rated power (MW) & 5 \\
\hline Cut-in wind speed (m/s) & 3 \\
\hline Rated wind speed (m/s) & 11.4 \\
\hline Cut-off wind speed (m/s) & 25 \\
\hline Rotor diameter (m) & 127.5 \\
\hline Hub height (m) & 90 \\
\hline Maximum $C_{P}$ & 0.466 \\
\hline Conversion loss coefficients & Quadratic $=0$, Linear $=0.055$, Constant $=0.02$ \\
\hline
\end{tabular}


Table 6. Cont.

\begin{tabular}{cc}
\hline Term & Description \\
\hline & Monopile-type foundation \\
\hline Steel cost $(\$ / \mathrm{kg})$ & 0.751 \\
Steel density $\left(\mathrm{kg} / \mathrm{m}^{3}\right)$ & 7870 \\
Monopile diameter $(\mathrm{m})$ & 5.5695 \\
Monopile thickness $(\mathrm{m})$ & 0.075 \\
\hline Size & Wind farm \\
\hline Configuration & $100 \mathrm{MW}$ \\
Spacing between WTs & 2 WTs $\times 10 \mathrm{WTs}$ \\
\hline Wind shear exponent & 10 diameters $\times 10$ diameters \\
Air density $\left(\mathrm{kg} / \mathrm{m}^{3}\right)$ & Others \\
Submarine cable loss coefficient & 0.143 \\
Availability & \multicolumn{2}{c}{1.228} \\
& Internal $=0.025$, External $=0.04$ \\
\end{tabular}

Table 7. Financial assumptions.

\begin{tabular}{cc}
\hline Item & Figure \\
\hline Inflation rate & $3 \%$ \\
Nominal discount rate & $7.12 \%$ \\
Corporate tax rate & $22 \%$ \\
Loan fraction & $65 \%$ \\
Loan interest rate & $4 \%$ \\
Amortization period (years) & 10 \\
Grace period (years) & 3 \\
Depreciation period (years) & 15 \\
Construction period (years) & 3 \\
Operations period (years) & 20 \\
\hline
\end{tabular}

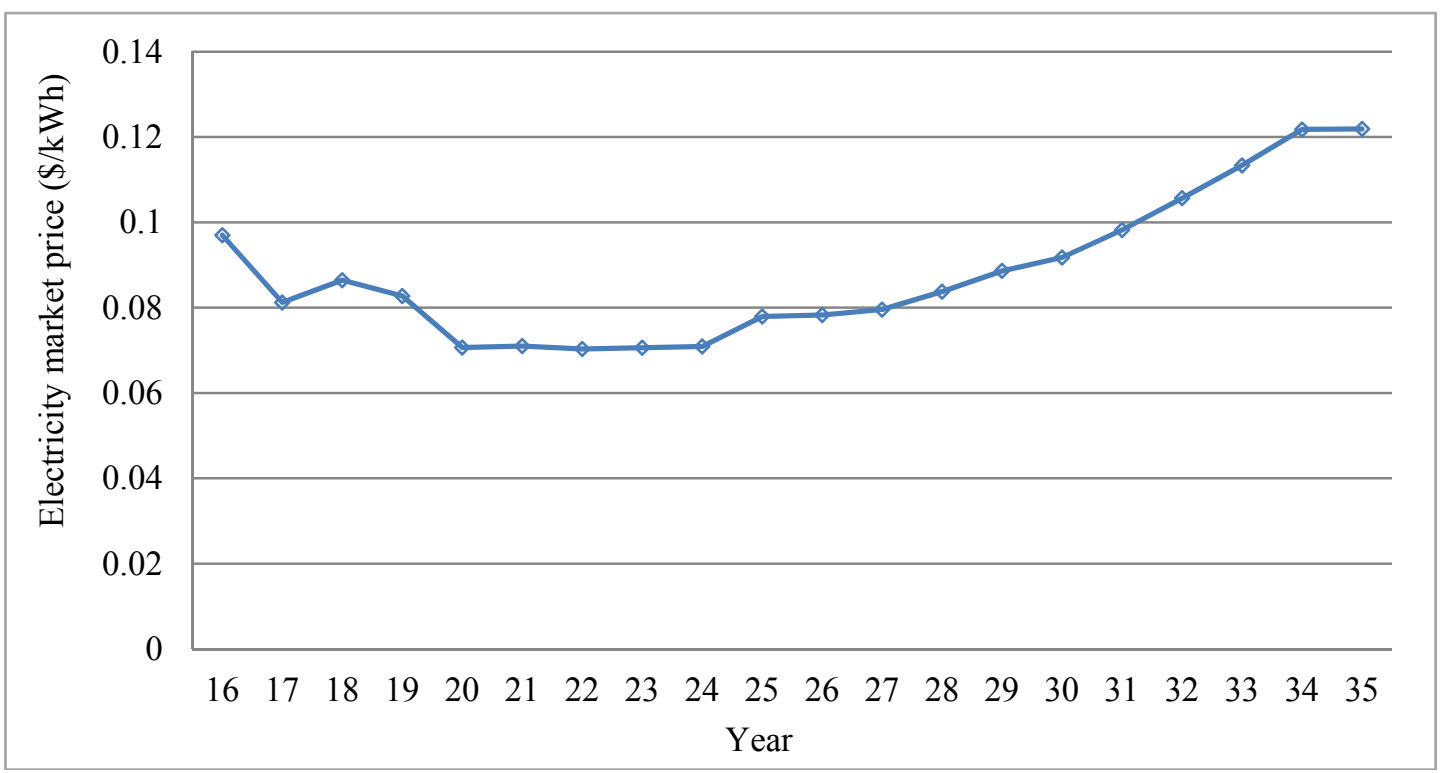

Figure 7. Predicted electricity market price. 
Figure 8 shows the predicted REC price considering the marginal cost, energy production, REC weighting, and MMF [5], as well as the electricity generation extrapolated using a second-order polynomial function with the largest coefficient of determination. It has been confirmed that the REC price was determined from the average cost of a fuel cell from 2016 to 2019, and then from the unit cost of wind energy until 2035.

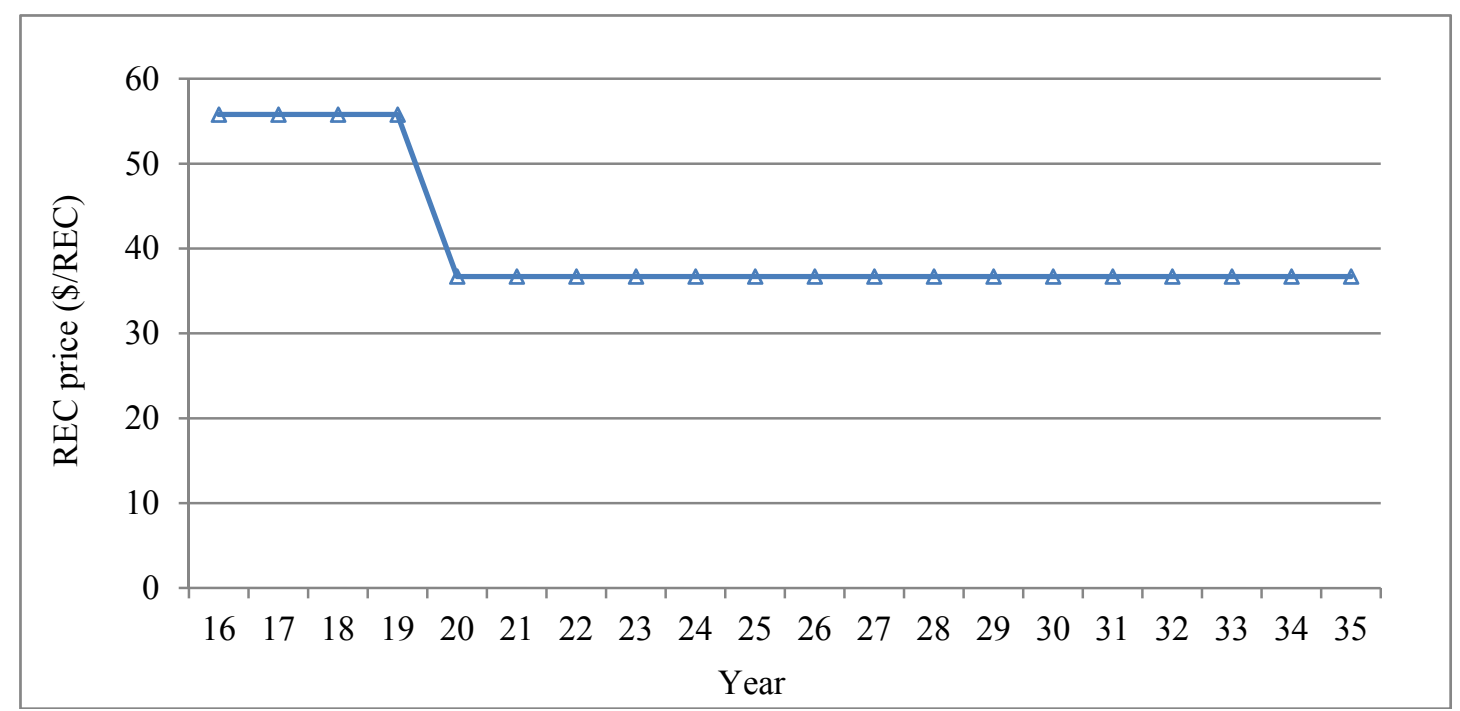

Figure 8. Predicted REC price.

Scenarios for RPS should be adjusted based on practical grounds. The existing RPS is suitable for immediate modification by adjusting the MMF and/or the weightings for renewable energy resources. Thus, we consider the scenarios for RPS to investigate the economic viability of the adjusted RPS compared with the existing RPS listed in Table 8. The MMF and REC weighting of wind energy were chosen as parameters for all the scenarios. The original value for each parameter is represented as $F$ and $W$, respectively. The economic evaluation for each scenario was performed so that one parameter varied while the remaining parameters were fixed. The offshore WF was assumed to operate from 2016 to 2035 following the completion of its construction in 2015.

Table 8. Scenarios for the RPS.

\begin{tabular}{cc}
\hline Scenario 1: Adjustment for REC Weighting & Scenario 2: Adjustment for MMF \\
\hline$W-1.25$ & $F-2.5 \%$ \\
$W-1.0$ & $F-2.0 \%$ \\
$W-0.75$ & $F-1.5 \%$ \\
$W-0.5$ & $F-1.0 \%$ \\
$W-0.25$ & $F-0.5 \%$ \\
$W$ & $F$ \\
$W+0.25$ & $F+0.5 \%$ \\
$W+0.5$ & $F+1.0 \%$ \\
$W+0.75$ & $F+1.5 \%$ \\
$W+1.0$ & $F+2.0 \%$ \\
$W+1.25$ & $F+2.5 \%$ \\
\hline
\end{tabular}


The results show that the existing support schemes yield a negative NPV ( $-6066 \mathrm{k} \$$ ) and an IRR of $6.77 \%$, which is smaller than the nominal discount rate. To explore improvements in the current RPS, the economic feasibility of each scenario was investigated, as shown in Figures 9 and 10. By making changes to REC supply for wind energy, the REC weighting did influence the REC revenue, as shown in Figure 9. As shown in Figure 10, the NPVs and IRRs for the new and original MMFs were almost unchanged from $F-2.5 \%$ to $F-0.5 \%$. This is because the REC price did not change, although the REC demand decreased in response to changes in the MMF. In contrast to the NPV and IRR, the nominal value of the LCOE was constant at $0.1627 \$ / \mathrm{kWh}$, regardless of adjustments to the revenue-related elements for all scenarios.
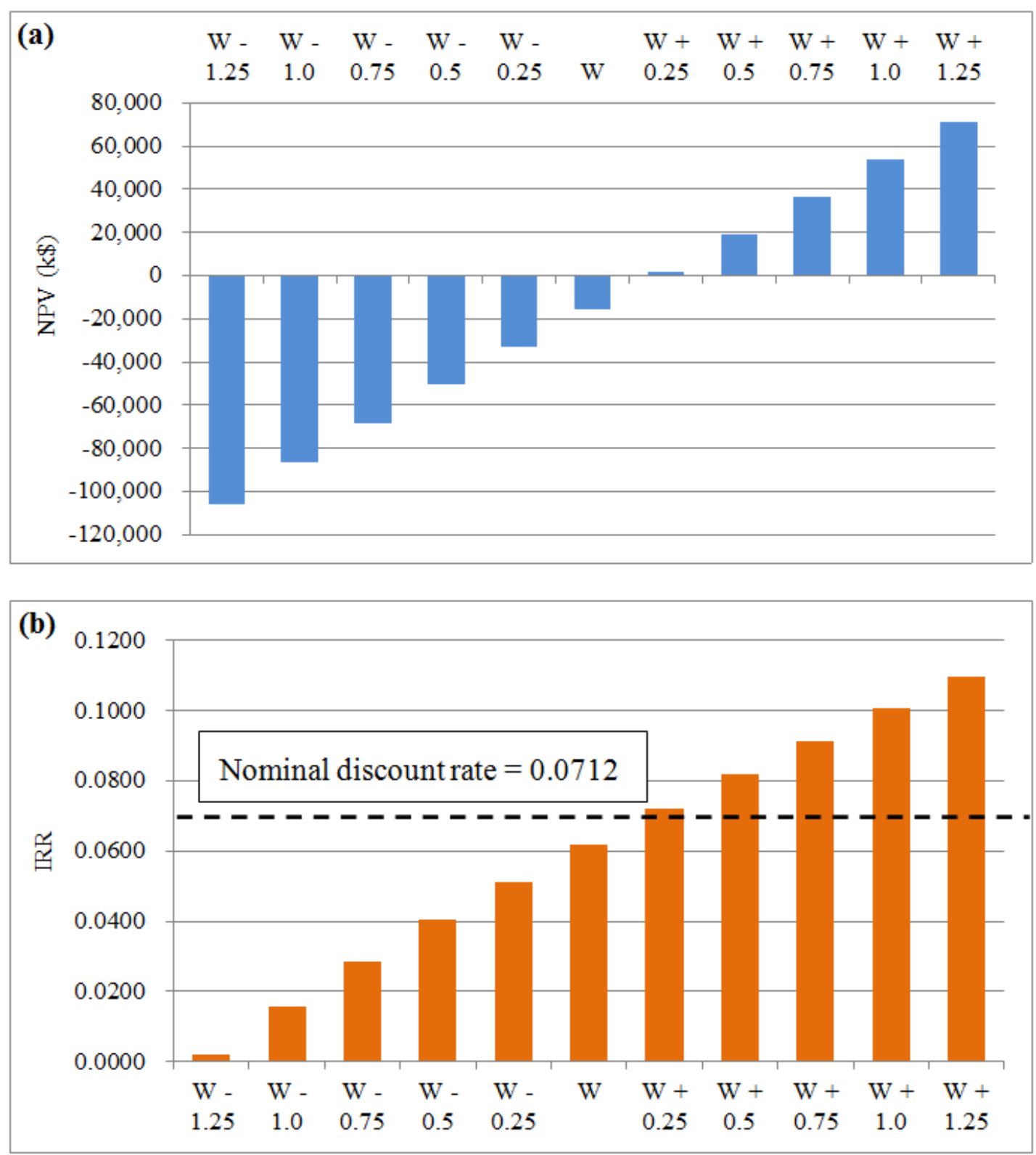

Figure 9. NPV (a) and IRR (b) in Scenario 1. 

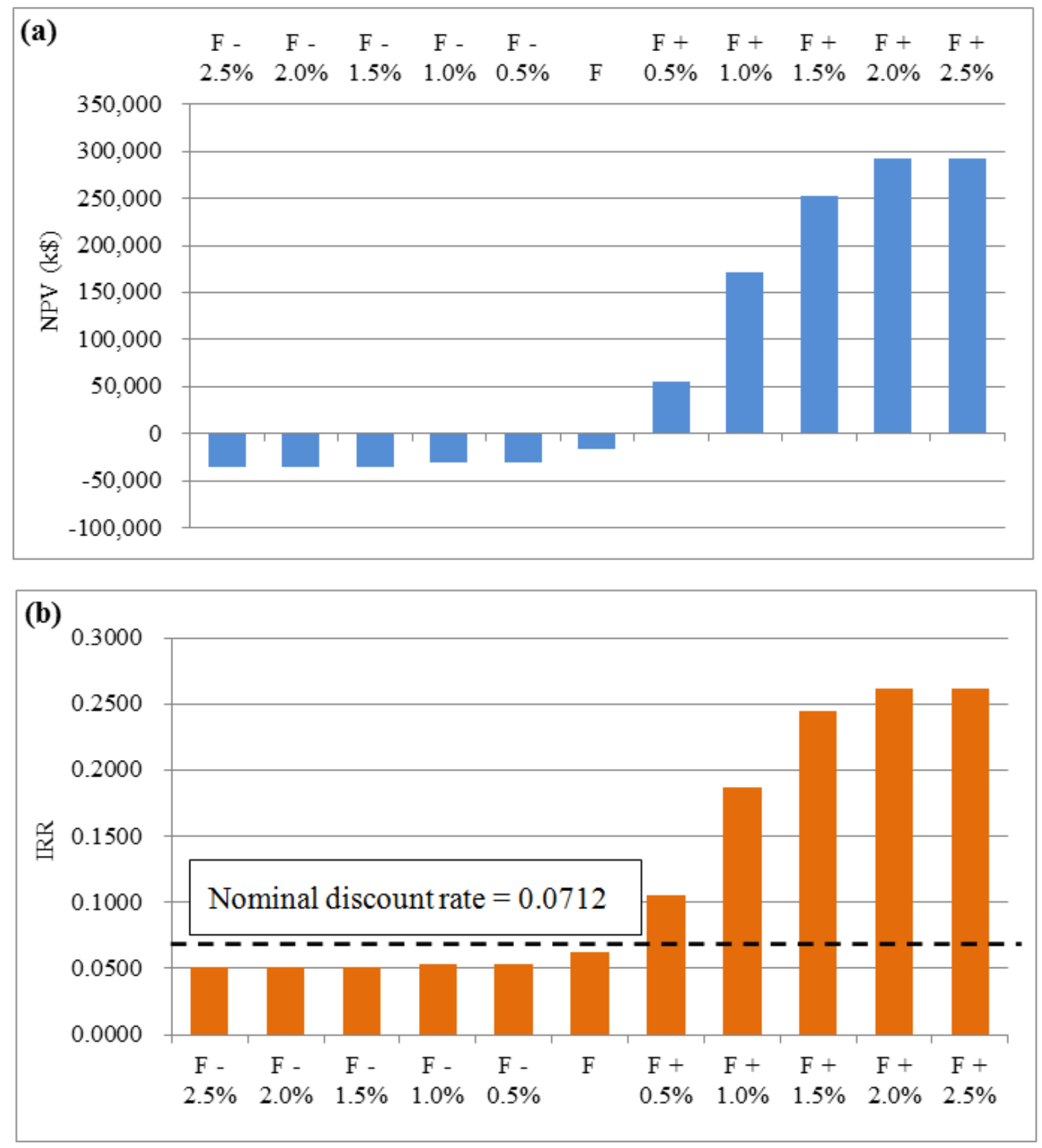

Figure 10. NPV (a) and IRR (b) in Scenario 2.

\section{Conclusions}

The motivation of our study was to investigate whether the RPS currently in force is effective to promote the expansion plan which focuses on the penetration of offshore WFs in Korea. It is vital to consider whether existing RPS is suitable to offer a favorable environment for investment. In this paper, we proposed a framework to assess the economic viability of RPS considering long-term changes in revenue elements. We investigated the feasibility of options for adjusting existing RPS. The electricity market price and REC price in Korea were predicted based on the sixth basic plan for long-term electricity supply and demand. The results showed that existing RPS would have a limited ability to help enhance the penetration of offshore WFs. The adjusted RPS, however, were shown to be beneficial to increasing the economic viability of offshore WFs. The approach described here is not 
limited to Korea, and it may be extendable to other countries; as part of our future work, we plan to extend our method to consider the long-term development of energy markets in other countries.

\section{Acknowledgments}

This work was supported by the National Research Foundation of Korea (NRF) grant funded by the Korea government (MSIP) (2010-0028509).

\section{Author Contributions}

Chang-Gi Min carried out the main body of research and Jong Keun Park reviewed the work continuously. Don Hur contributed with specialised engineering knowledge and Mun-Kyeom Kim provided essential information.

\section{Conflicts of Interest}

The authors declare no conflict of interest.

\section{Nomenclature}

$\begin{array}{ll}\text { AWEP } & \text { Annual wind energy production } \\ A W E P_{W F} & \text { AWEP of a WF } \\ A W E P_{W T} & \text { AWEP of a WT } \\ C_{i} & \text { Cumulative sum of installed capacities of all conventional generators up to the } i \text { th } \\ & \text { conventional generator } \\ d L & \text { Infinitesimal increment in load } \\ \text { EPP } & \text { Electric power producer } \\ f_{C, i} & \text { PDF of unavailable capacity of } i \text { th conventional generator } \\ f_{i} & \text { PDF of equivalent load of } i \text { th conventional generator } \\ \text { FIT } & \text { Feed-in tariff } \\ f_{L} & \text { PDF of original load } \\ \text { FOR } & \text { Forced outage rate } \\ F O R i & \text { FOR of } i \text { th conventional generator } \\ f_{P, \#} & \text { PDF of output of PF \# multiplied by }-1 \\ f_{W, \#} & \text { PDF of output of WF \# multiplied by }-1 \\ f_{W P} & \text { PDF of equivalent load incorporating } M \text { WFs and } N \text { PFs } \\ I & \text { Index of conventional generator } \\ \text { IRR } & \text { Internal rate of return } \\ K & \text { Index for type of renewable energy resource } \\ \text { LCOE } & \text { Levelized cost of energy } \\ M & \text { Number of WFs } \\ \text { MMF } & \text { Mandatory minimum fraction } \\ N & \text { Number of PFs } \\ N c & \text { Number of conventional generators } \\ & \end{array}$




$\begin{array}{ll}\text { NPV } & \text { Net present value } \\ \text { PDF } & \text { Probability density function } \\ \text { PF } & \text { PV farm } \\ \text { PPC } & \text { Probabilistic production cost } \\ \text { PV } & \text { Photovoltaic } \\ \text { REC } & \text { Renewable energy certificate } \\ \text { RPS } & \text { Renewable portfolio standard } \\ T & \text { Year of operation of WF } \\ \text { WF } & \text { Wind farm } \\ \text { WT } & \text { Wind turbine }\end{array}$

\section{References}

1. The Ministry of Knowledge Economy. The 6th Basic Plan on Electricity Demand and Supply; The Ministry of Knowledge Economy: Sejong City, Korea, 2013.

2. $\mathrm{Yu}, \mathrm{J} .-\mathrm{H}$. Special issues on wind-roadmap for promoting offshore wind power. J. Electr. World 2010, 408, 56-59.

3. Lee, S.-M.; Han, H.-S. Benefit-cost analysis of biodiesel production in Korea. J. Rural Dev. 2008, $31,49-65$.

4. Chen, W.-M.; Kim, H.; Yamaguchi, H. Renewable energy in Eastern Asia: Renewable energy policy review and comparative SWOT analysis for promoting renewable energy in Japan, South Korea, and Taiwan. Energy Policy 2014, 74, 319-329.

5. Hwang, S.; Kwon, J.; Ahn, J.; Woo, P.-S.; Kim, B.H. A study on the rec price for the RPS. In Proceedings of the 43th the KIEE Summer Annual Conference, Gangwon-do, Korea, 18-20 July 2012; pp. 352-354.

6. Korea Power Exchange (KPX). Annual Market Operation Data; KPX: Seoul, Korea, 2013.

7. Cutler, N.J.; Boerema, N.D.; MacGill, I.F.; Outhred, H.R. High penetration wind generation impacts on spot prices in the australian national electricity market. Energy Policy 2011, 39, 5939-5949.

8. Morales, J.M.; Conejo, A.J.; Perez-Ruiz, J. Simulating the impact of wind production on locational marginal prices. IEEE Trans. Power Syst. 2011, 26, 820-828.

9. Rahimiyan, M. A statistical cognitive model to assess impact of spatially correlated wind production on market behaviors. Appl. Energy 2014, 122, 62-72.

10. Vilim, M.; Botterud, A. Wind power bidding in electricity markets with high wind penetration. Appl. Energy 2014, 118, 141-155.

11. Pereira, A.J.; Saraiva, J.T. Long term impact of wind power generation in the Iberian day-ahead electricity market price. Energy 2013, 55, 1159-1171.

12. Rubin, O.D.; Babcock, B.A. The impact of expansion of wind power capacity and pricing methods on the efficiency of deregulated electricity markets. Energy 2013, 59, 676-688.

13. Lind, A.; Rosenberg, E.; Seljom, P.; Espegren, K.; Fidje, A.; Lindberg, K. Analysis of the EU renewable energy directive by a techno-economic optimisation model. Energy Policy 2013, 60, 364-377. 
14. Sawhney, R.; Thakur, K.; Venkatesan, B.; Ji, S.; Upreti, G.; Sanseverino, J. Empirical analysis of the solar incentive policy for Tennessee solar value chain. Appl. Energy 2014, 131, 368-376.

15. Wiser, R.; Barbose, G.; Holt, E. Supporting solar power in renewables portfolio standards: Experience from the United States. Energy Policy 2011, 39, 3894-3905.

16. Menz, F.C.; Vachon, S. The effectiveness of different policy regimes for promoting wind power: Experiences from the states. Energy Policy 2006, 34, 1786-1796.

17. Kim, J.-H. A New Investment Game Modeling for Competitive Electricity Market Anaysis; Seoul National University: Seoul, Korea, 2001.

18. New \& Renewable Energy Center. The Rules of Issue and Trading Market Operation of Renewable Energy Certificate (REC); New \& Renewable Energy Center: Gyeonggi-do, Korea, 2012.

19. Aggarwal, S.K.; Saini, L.M.; Kumar, A. Electricity price forecasting in deregulated markets: A review and evaluation. Int. J. Electr. Power Energy Syst. 2009, 31, 13-22.

20. Ercan, P.; Soto, J. A Model for Long Term Electricity Price Forecasting for France; KTH Royal Institute of Technology: Stockholm, Sweden, 2012.

21. Wang, H.; Liu, X.; Wang, C. Probabilistic production simulation of a power system with wind power penetration based on improved UGF techniques. J. Mod. Power Syst. Clean Energy 2013, 1, 186-194.

22. Lin, M.; Breipohl, A.; Lee, F. Comparison of probabilistic production cost simulation methods. IEEE Trans. Power Syst. 1989, 4, 1326-1334.

23. New \& Renewable Energy Center. Renewable Portfolio Standard. Available online: http://www. knrec.or.kr/knrec/12/KNREC120700_02.asp (accessed on 20 May 2015).

24. Fingersh, L.J.; Hand, M.M.; Laxson, A.S. Wind Turbine Design Cost and Scaling Model; National Renewable Energy Laboratory: Golden, CO, USA, 2006.

25. Min, C.G.; Hur, D.; Park, J.K. Economic Evaluation of Offshore Wind Farm in Korea. J. Electr. Eng. Technol. 2014, 63, 1192-1198.

26. Cost Estimation Committee. Technical Data of Dispatchable Generators; KPX: Seoul, Korea, 2008.

27. Park, S.M.; Choi, K.R.; Park, Y.G. A study on the change of power generation mix and $\mathrm{CO}_{2}$ reduction cost by the difference of IGCC efficiency and nuclear power generation. In Proceedings of the Korea Energy and Climate Change Conference, Seoul, Korea, 4-5 December 2009; pp. 147-152.

28. Kim, S.-S.; Park, J.-B.; Jung, H.-S.; Lee, W.-N. A Study on Estimation Method for Standard Capacity Price and Regional Capacity Factor; The Ministry of Knowledge Economy: Sejong City, Korea, 2009.

29. Korea Meteorological Administration. National climate data service system. Available online: http://sts.kma.go.kr/jsp/home/contents/climateData/obs/obsValSearch.do?MNU=MNU (accessed on 20 May 2015).

30. Green, M.A.; Emery, K.; Hishikawa, Y.; Warta, W.; Dunlop, E.D. Solar cell efficiency tables (version 39). Prog. Photovolt. Res. Appl. 2012, 20, 12-20.

31. Notton, G.; Lazarov, V.; Stoyanov, L. Optimal sizing of a grid-connected PV system for various PV module technologies and inclinations, inverter efficiency characteristics and locations. Renew. Energy 2010, 35, 541-554. 
32. Skoplaki, E.; Palyvos, J. Operating temperature of photovoltaic modules: A survey of pertinent correlations. Renew. Energy 2009, 34, 23-29.

33. Kim, H.-G.; Kang, Y.-H. 2010 wind resource map of the Korean peninsula. J. Wind Eng. Inst. Korea 2012, 16, 167-172.

34. Jonkman, J.M.; Butterfield, S.; Musial, W.; Scott, G. Definition of a 5-mw Reference Wind Turbine for Offshore System Development; National Renewable Energy Laboratory: Golden, CO, USA, 2009.

35. Vestas. V110-2.0 $\mathrm{mw}^{\mathrm{TM}}$ at a glance. Available online: http://www.vestas.com/en/products_and_ services/turbines/v110-2_0_mw\#!technical-specifications (accessed on 20 May 2015).

36. Korea Meteorological Administration. Wind resource map. Available online: http://www.kma.go.kr/ weather/climate/wind_map.jsp (accessed on 20 May 2015).

37. National Geographic Information Institute. National land and territory map. Available online: http://www.land.go.kr/portal/subMain/mainContentsPage/nationMap/bookContents/book2.do?idx=02 (accessed on 20 May 2015).

38. Korea Electric Power Company (KEPCO). Trends and Prospects of Offshore Wind Farm in Korea; KEPCO: Seoul, Korea, 2011.

39. Kikuchi, Y.; Ishihara, T. An assessment of offshore wind energy potential considering economic feasibility in Kanto region, Japan. In Proceedings of the European Wind Energy Conference, Copenhagen, Denmark, 16-19 April 2012.

40. Kim, J.-Y.; Oh, K.-Y.; Kang, K.-S.; Lee, J.-S. Site selection of offshore wind farms around the Korean peninsula through economic evaluation. Renew. Energy 2013, 54, 189-195.

41. Korea Power Exchange (KPX). Electricity Market Trends \& Analysis 2013, Annual Report; KPX: Seoul, Korea, 2014.

(C) 2015 by the authors; licensee MDPI, Basel, Switzerland. This article is an open access article distributed under the terms and conditions of the Creative Commons Attribution license (http://creativecommons.org/licenses/by/4.0/). 